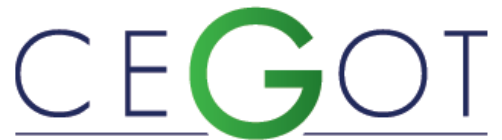

Centro de Estudos de Geografia e Ordenamento do Território
Geografia e Ordenamento do Território, Revista Eletrónica Centro de Estudos de Geografia e Ordenamento do Território http://cegot.org

Colavite, AnA

Universidade Estadual do Paraná / Colegiado de Geografia e Laboratório de Geoprocessamento e Sensoriamento Remoto 87.302-060, Av. Comendador Norberto Marcondes, 733, Campo Mourão, Paraná, Brasil apcolavite@hotmail.com

\author{
MASSOQUIM, NAIR \\ Universidade Estadual do Paraná / Colegiado de Geografia e \\ Laboratório de Geoprocessamento e Sensoriamento Remoto \\ 87.302-060, Av. Comendador Norberto Marcondes, 733, Campo Mourão, \\ Paraná, Brasil \\ nmassoquim@gmail.com \\ GONÇALVES, MARIANA \\ Universidade Estadual do Paraná / Especialização em \\ Geografia, Meio Ambiente e Ensino \\ 87.302-060, Av. Comendador Norberto Marcondes, 733, Campo Mourão, \\ Paraná, Brasil \\ mary colavite@hotmail.com
}

\title{
Paisagem e produção agrícola regional: uma análise a partir de mapas temáticos da Mesorregião Centro Ocidental Paranaense, Sul do Brasil \\ Landscape and regional agricultural production: an analysis based on thematic maps of the western central mesoregion of Parana, Southern Brazil
}

Referência: Colavite, Ana; Massoquim, Nair; Gonçalves, Mariana (2018). Paisagem e produção agrícola regional: uma análise a partir de mapas temáticos da Mesorregião Centro Ocidental Paranaense, Sul do Brasil. Revista de Geografia e Ordenamento do Território (GOT), n. ${ }^{\circ} 14$ (setembro). Centro de Estudos de Geografia e Ordenamento do Território, p.135158, dx.doi.org/10.17127/got/2018.14.005

\section{RESUMO}

$\mathrm{Na}$ pesquisa teve-se como objetivo realizar o mapeamento de variáveis relacionadas à produção agrícola municipal, da Mesorregião Centro Ocidental Paranaense (localizada no Sul do Brasil), identificando os tipos de cultivo que predominam regionalmente e sua distribuição espacial, associada às condições geográficas e paisagísticas. O processo de mapeamento ocorreu com o aporte do QGis e os dados foram obtidos no IBGE. A analise considerou as correlações entre os padrões de distribuição da agricultura, associados às caracteristicas da paisagem regional. Com base no mapeamento, foi possível identificar o predomínio dos cultivos da soja e do milho, a exceção de alguns municípios, nos quais o relevo é mais dissecado e os solos são frágeis, em que há o predominio da pecuária e tem adquirido status a fruticultura.

Palavras-chave: Cartografia Temática;Impactos socioambientais; Agricultura; Fragilidade Ambiental; Potencial de uso da terra; Desenvolvimento Regional.

\section{ABSTRACT}

The research had the objective of mapping the variables related to municipal agricultural production of the Western Central Mesoregion of Parana (in Southern Brazil), identifying 
the types of farming that are predominant regionally and its spatial distribution, associated to geographical and landscape conditions. The mapping process occurred with the input of QGIS and the data were obtained from IBGE. The analysis took into account the correlation between the agriculture distribution patterns alongside the characteristics of regional landscape. Based on the mapping it was possible to identify the predominance of soybean and corn farming, except for some municipalities, where topography is dissected and soils are fragile, where there is predominance of livestock farming and fruit farming has increased.

Keywords: Thematic Cartography; Socioenvironmental impacts; Agriculture; Environmental vulnerability; Potential land use; Regional Development.

\section{Introdução}

As paisagens são resultantes da combinação dinâmica de elementos do meio natural, os quais interagem, conferindo ao ambiente distintos graus de potencialidade no uso da terra (BERTRAND, 1972; SOTCHAVA, 1977) e, consequentemente, fragilidades. Entretanto, uma paisagem não se restringe apenas ao meio físico e aos recursos de exploração natural, mas nas diversas formas de ocupação socioespacial organizadas pelo homem (TRICART, 1977).

As sociedades são protagonistas nos processos de construção, modificação e transformação das paisagens, imprimindo nestas, suas caracteristicas culturais, seu modo de ser e viver, bem como registrando o domínio de técnicas e tecnologias, que varia no decorrer do tempo (SAUER, 2004; PASSOS, 1998). As paisagens são reflexos das identidades culturais e seus ambientes naturais apresentam potencial para serem transformados em múltiplas paisagens, entretanto as mudanças têm como base as definições culturais dos grupos que ali se encontram (GREIDER, GARKOVICH, 1994).

Essas relações de uso e interação do homem com a paisagem levaram Maximiano (2004, p.89) a afimar que "a visão da paisagem sempre teve um aspecto utilitarista para praticamente todos os povos e em todas as épocas". E, neste contexto, Fajardo (2008, p.20) coloca que "[...] os processos de ordem econômica afetam diretamente os aspectos visíveis da paisagem além dos próprios processos naturais combinados no interior da mesma". E, para Passos et al (2012), o dinamismo das sociedades atuais e a fluidez e intensidade de suas atividades (exploração desenfreada dos recursos naturais, novos usos do solo, 
instalação de grandes infraestruturas, dentre outras variáveis) são indutoras de transformações das paisagens.

Ao discutir as relações entre agricultura e desenvolvimento Sayer et al (2012) salientam que a abordagem paisagística deve ser considerada, e o meio termo entre o uso e a exploração dos recursos deve ser atingido, atendendo as demandas sociais sem, todavia, renunciar à conservação da natureza, este constituiria o campo de análise das paisagens multifuncionais. Embora o desenvolvimento da agricultura seja fundamental para atender a demanda mundial por alimentos, e tem sido impar na dinâmica socioeconômica do Brasil, faz-se importante analisar sua distribuição espacial, para compreender como tem interferido na constituição das paisagens regionais.

$\mathrm{Na}$ pesquisa, teve-se como objetivo realizar o mapeamento temático de variáveis relacionadas à produção agrícola dos municípios da Mesorregião Centro Ocidental Paranaense. Com base nos mapas elaborados, identificaram-se os tipos de cultivos que predominam regionalmente e sua distribuição espacial associada às condições geográficas e paisagísticas. A importância do mapeamento temático esta na análise que se pode elaborar sobre o que é pesquisado em determinada área de conhecimento (NASCIMENTO, 2010), neste caso, as relações entre a agricultura e a paisagem e sua distribuição regional.

A Mesorregião Centro Ocidental Paranaense, recorte espacial da pesquisa, é formada por 25 municípios, localizada no sul do Brasil (Figura 1). A paisagem da Mesorregião apresenta elevada complexidade, resultante de inúmeras interações, sendo considerada também uma paisagem de transições, tanto nos elementos da natureza, quanto nos relativos ao processo histórico de ocupação e colonização (MASSOQUIM, 2010). Os municípios constituintes da pesquisa tiveram seu desenvolvimento econômico fortemente alicerçado no meio rural, o que nos levou a buscar compreender as correlações entre paisagem e agricultura, e suas influências no desenvolvimento regional.

A proposta de mapear variáveis relacionadas aos produtos agrícolas cultivados, nos municípios da mesorregião, teve como intuito compreender quais cultivos tiveram maior expressividade regional (área total colhida) e os valores obtidos com a produção, para, desta forma, entender a rentabilidade e a participação na economia dos municípios. Ademais, se 
buscou identificar a influência dos elementos da paisagem no desenvolvimento agrícola regional, identificando as correlações espaciais existentes.

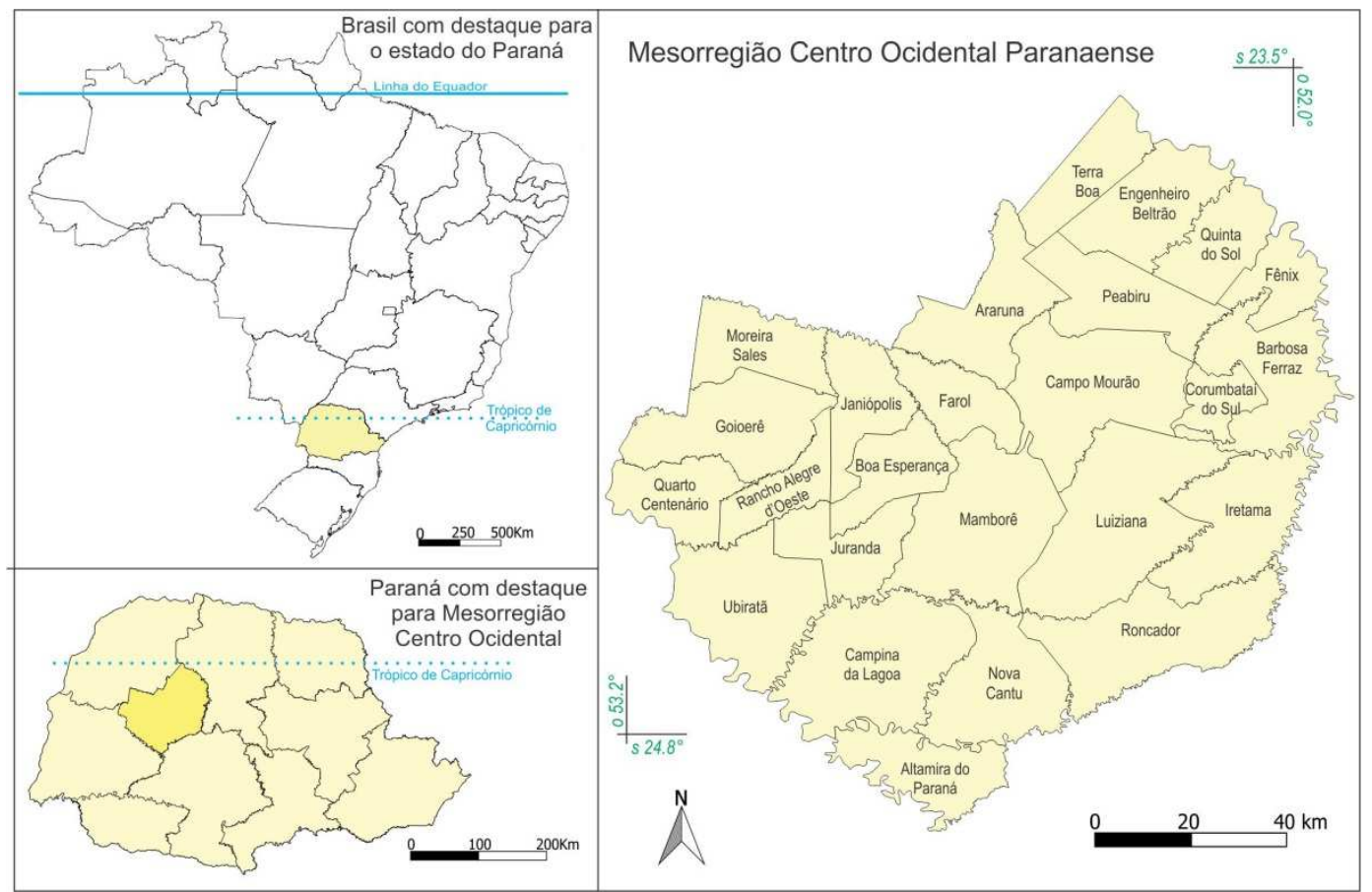

Figura 1 - Localização da Mesorregião Centro Ocidental Paranaense

Fonte: Base cartográfica - IBGE 2010

\section{Paisagem e agricultura}

O setor agrícola do Brasil figura no cenário internacional como um dos mais significativos na produção de grãos, especialmente destinados à exportação, destacando-se a relevância que tem adquirido a cultura da soja, do milho e da cana-de-açucar. De acordo com a Embrapa (2018), o Brasil é o segundo maior produtor mundial de soja e o terceiro de milho. 0 investimento na monocultura de grãos, destinados à exportação, faz parte do pacote tecnológico de mudanças promovidas pela modernização da agricultura brasileira, que teve início, no cenário nacional, em fins da década de 1960 ao início da de 1970 (GRAZIANO DA SILVA, 1980; LACERDA, 1983; MORO, 2001), repercutindo na dinâmica socioespacial regional (HESPANHOL, 1993; ANDRADE, 2013), com mudanças significativas na paisagem agrícola (MASSOQUIM, 2010; COLAVITE, 2013; YOKOO, 2013).

De acordo com Moro (2001), a modernização da agricultura promoveu alterações significativas nas práticas do agricultor, dentre as quais se destacam: mecanização; 
eletrificação (implantação de rede de energia elétrica no espaço rural); irrigação; práticas de manejo e conservação do solo; uso de fertilizantes e agrotóxicos; redução drástica do quantitativo da mão de obra. Decorrentes do processo supracitado, Jacinto et al (2012) destacam que, surgiram, a partir da década de 1980, mudanças significativas no meio rural brasileiro, emergindo um espaço multifuncional com a introdução de uma maior diversificação econômica, em meio as novas formas de produção e subsistência, em visível contraste com o que dominava no passado. Esta nova dinâmica, imposta ao mundo rural, produziu inúmeros reflexos na paisagem, acarretando rápida transformação, com a incorporção de novos padrões de uso, os quais se mantiveram e se intensificaram até os dias atuais.

É possível constatar que os problemas derivados do modelo de desenvolvimento (rural, local e regional) adotado pelo país, com base na modernização das atividades agropecuárias, agravaram os problemas sociais, ambientais, econômicos e políticos (Ferreira et al, 2016). Essa perspectiva converge para o reconhecimento "[...] de que a produção em grande escala, vinculada ao abastecimento de mercados globais, estaria levando a uma redução nos índices de emprego e renda e a uma pequena diversificação das atividades econômicas em seu entorno" (NORDER, 2006, p. 58).

Para Sunderland (2011), a ampliação das áreas destinadas à produção de alimentos, tem ocorrido de forma convencional convertendo áreas naturais em áreas agrícolas, especialmente nas regiões tropicais, promovendo a homogeneização dessas paisagens. Como resultado imediato dessas ações, tem ocorrido perda significativa da biodiversidade e dos serviços ecossistêmicos relacionados (TSCHARNTKE et al, 2005).

Outro aspecto de grande relevância nesta discussão consiste nas relações e alterações, estabelecidas entre os espaços rural e urbano nas ultimas décadas. Ainda que no Brasil tenha havido uma drástica inversão da relação entre população rural e população urbana, com expressiva ampliação desta última, o país e, especialmente, as pequenas cidades do interior, tem sua economia alicerçada na produção agropecuária e nos subprodutos agregados a essa atividade. Hespanhol (2008, p. 88) reforça esta ideia ao expressar que "o dinamismo econômico das cidades interioranas depende, essencialmente, do desempenho da agricultura". Realidades essas vivenciadas pelos municípios constituintes da Mesorregião pesquisada. 
A agricultura consiste em uma forma de produção da paisagem, portanto, ao analisá-la é possível reconhecer os modos de organização espacial da atividade agrícola em um determinado território (Andrade, 2005). A esta ideia, acrescentamos a reflexão de Fajardo (2008, p. 21) ao expor que "[...] fatores de ordem econômica atuam como elemento antrópico decisivo na combinação resultante de uma paisagem rural característica".

Conforme se ampliou a inserção de capital, as atividades agrícolas brasileiras foram se expandindo e as transformações da paisagem se tornaram amplamente perceptíveis. Mesmo quando buscamos compreender essas transformações em escala local ou regional, enfatiza-se, elas não ocorrem ao acaso, são resultantes de escolhas e conjunturas nacionais e internacionais, do interesse econômico e do modelo politico vigente.

As ações na paisagem são articuladas e mediadas por agentes territoriais e, no caso da atual discussão, enfatizamos o papel das grandes cooperativas agroindustriais nesse processo e de pequenas e novas cooperativas buscando resistir e territorializar os espaços não atingidos, ou de baixo interesse às grandes cooperativas. Neste viés, recorremos a Raffestin (2009, p. 15) ao expor que "a paisagem é um produto da territorialidade que resulta de um conjunto de relações mediatizadas, produto expresso por meio de diversas linguagens, em certa escala".

Os mapas temáticos permitem reconhecer como os elementos estão distribuidos no território, manifestado em suas múltiplas escalas (do local ao global), portanto, a análise regional, de um ou mais elementos da paisagem, deve pautar-se em produtos cartográficos que indiquem as correlações espaciais existentes e como o espaço está organizado. Neste contexto, para Silva et al (2014, p. 95) “A partir das representações cartográficas elaboradas em ambiente SIG, é possível analisar de modo mais coerente às particularidades de uma área ou região, possibilitando assim o fornecimento de subsídios para o planejamento, assim como para formulação de políticas públicas direcionadas para os diferentes setores da economia e segmentos sociais". 


\section{Materiais e Métodos}

O desenvolvimento metodológico da pesquisa partiu do pressuposto da interpretação analítica do desenvolvimento agrícola regional identificado nas representações cartográficas e em suas correlações com a dinâmica da paisagem. Neste contexto, os dados de produção e produtividade agrícola municipal, foram representados em mapas temáticos da Mesorregião Centro Ocidental Paranaense e a análise foi sobreposta ao mapeamento dos elementos da paisagem: Solos; Tipos climáticos; Subunidades morfoesculturais do relevo; Hipsometria e; Declividade (MASSOQUIM, 2010). Com base na sobreposição, analisou-se a distribuição dos cultivos agrícolas em sua correlação com a dinâmica da paisagem regional.

A pesquisa utilizou como base dados estatísticos disponibilizados pelo IBGE (Instituto Brasileiro de Geografia e Estatística), na plataforma de Produção Agrícola Municipal, para o ano de 2015 (IBGE, 2016). Foram selecionados os produtos da agricultura temporária e permanente, com as variáveis de área colhida e valor obtido com a produção. O processo de mapeamento procedeu no Qgis versão 2.16 (QGIS Development Team, 2016).

Seguindo as regras da cartografia temática, foram selecionados, por meio de testes, as melhores formas de: representação; agrupamento de dados; subdivisão da legenda; sobreposição de dados; grau de detalhamento e abstração, dentre outros. Com base nesses critérios utilizados, os mapas foram finalizados no editor de desenho do Corel Draw e então apresentados e analisados no tópico posterior.

\section{Resultados e discussões}

A partir da espacialização dos dados da produção agricola municipal, da Mesorregião Centro Ocidental Paranaense, constatou-se que a lógica da agricultura regional segue os padrões nacionais, no que tange aos produtos de maior destaque. Em todos os municípios da mesorregião observou-se o predomínio das áreas cultivadas com a soja e o milho. Ponderase ainda que, esses tipos de cultivos levam em consideração os aspectos fisicos, atributos de extrema relevância na paisagem regional, os fatores que contribuem para os altos índices de 
área colhida nesses municípios são a topografia do terreno, o tipo de solo e as condições climáticas.

Com relação à topografia do terreno (Figura 2 - Mapa de Geomorfologia e Mapa de Declividade), parcela considerável do território dos municípios situa-se na subunidade morfoescultural do relevo intitulada Planalto de Campo Mourão (MINEROPAR, 2006), dentre suas características principais destacam-se: baixos índices de declividade; topos aplainados com interflúvios largos; vertentes retilíneas e concavas na base e; vales em calha. A configuração topográfica dessa subunidade apresenta baixa fragilidade ambiental e maior resistência aos processos oriundos de atividades impactantes, o que tem permitido a ampla expansão da agricultura mecanizada. Associado a essas condições topográficas regionais, o tipo de solo predominante é o latossolo vermelho (Figura 2 - Mapa de Solos), este se caracteriza por ser profundo, poroso e de bom desenvolvimento radicular, quando eutrófico a fertilidade é mais elevada (EMBRAPA, 2006), ideal para as culturas de grãos.

Já as áreas dos municípios que se situam quase na integra na subunidade morfoescultural do relevo Planalto do Alto/Médio Piquiri (Figura 2 - Mapa de Geomorfologia e Mapa de Declividade), apresentam-se com declividades medianas e parcela de seu solo é classificada como neossolo, o formato das vertentes é convexo e convexo-concavo (facilitando a ocorrência de processos erosivos), os topos de morros são alongados e isolados e os vales em $U$ aberto. A fragilidade ambiental desta subunidade é mediana, constituindo áreas menos propícias a mecanização agrícola e com a necessidade de adoção de práticas conservacionistas mais intensas, nessas áreas o uso da terra se da com culturas diversificadas. Atenta-se para o fato de que, apesar destas áreas apresentarem fragilidade ambiental mediana, nos locais onde é possível a mecanização e a inserção de cultivos de grãos, estes são implantados, mesmo que em pequenas e isoladas parcelas do terreno (COLAVITE, MASSOQUIM, 2016).

Para a região, segundo o ITCG/IPARDES (2006), são predominantes os tipos climáticos Cfa e $\mathrm{Cfb}$ e em uma pequena parcela estão presentes o Cw e o Cwa, sentido noroeste (Figura 2 Mapa de Tipos Climáticos). A área de ocorrência do Cfb situa-se no interflúvio que divide topograficamente as bacias do rio Ivaí e Piquiri (importantes subbacias do rio Paraná), portanto, este tipo climático associa-se as áreas mais altas da mesorregião (Figura 2 - Mapa Hipsomético), coincidindo com os municípios mais propícios ao cultivo do trigo, cultura que 
exige temperaturas baixas de inverno. O tipo climático $\mathrm{Cfa}$ associa-se as áreas com menores cotas de altitudes, nos vales e baixas vertentes dos rios principais da área pesquisada. Em termos gerais, é possivel observar que a mesorregião situa-se em uma área de transição de tipo climático.

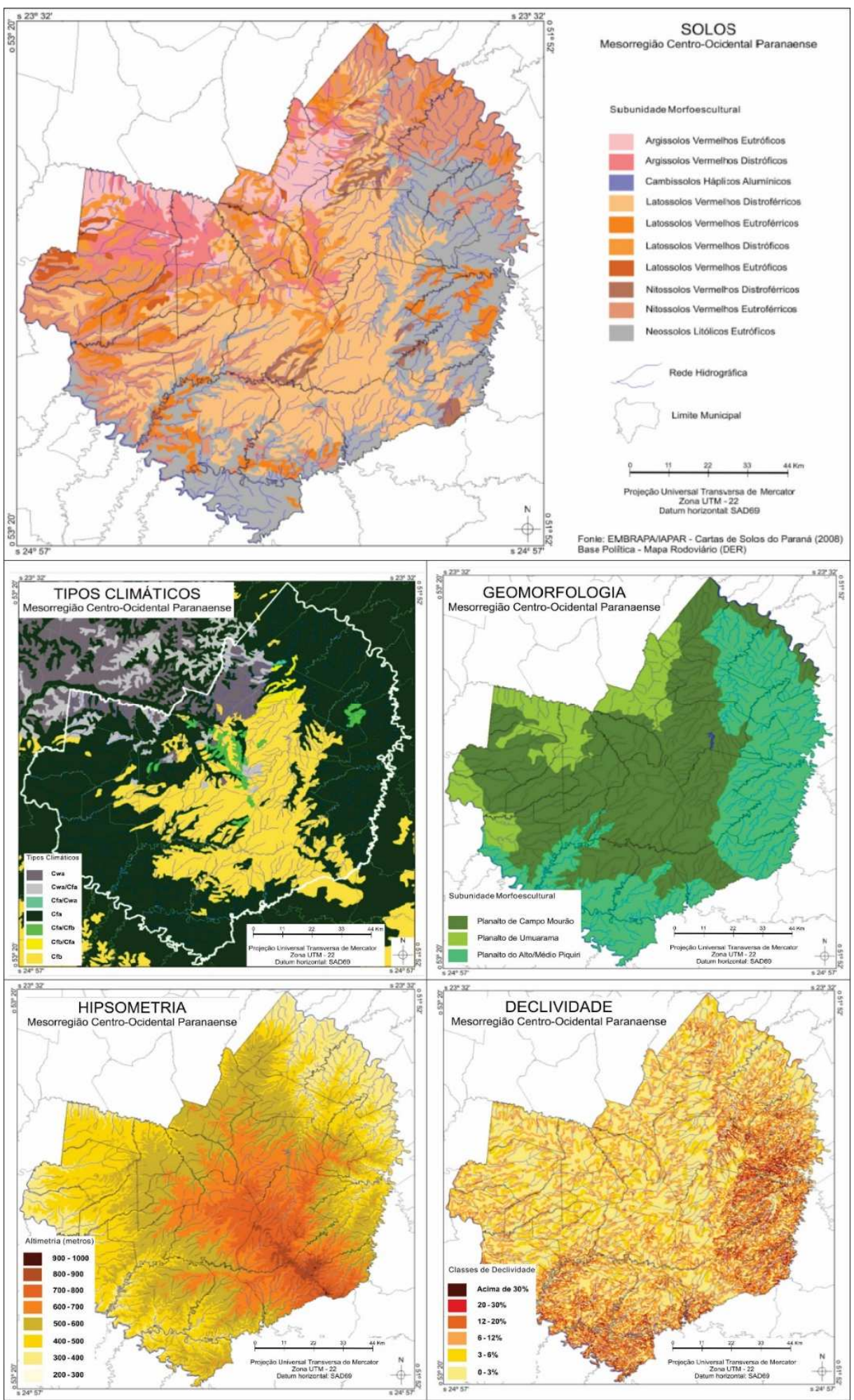

Figura 2: Conjunto de mapas representativos da dinâmica da paisagem regional Fonte: MASSOQUIM (2010) 
Neste sentido, a composição do sistema territorial natural, por meio das variáveis relevo, clima e pedologia, resulta em uma paisagem de extensas áreas com baixos e médios índices de declividade, predominância de solos profundos e férteis e o clima favorável ao desenvolvimento agrícola.

No conjunto de mapas temáticos da Figura 3, apresentam-se as áreas colhidas das culturas da soja, do milho, do trigo e da aveia, e o gráfico apresenta o valor obtido com cada um. A soja e o milho são considerados os principais produtos agrícolas e os mais expressivos na economia regional e nacional, o trigo e a aveia são produtos de consumo interno, e utilizam o mesmo espaço em períodos diferenciados, inverno (MASSOQUIM, 2010). Cabe destacar que, os produtos citados fazem parte da agricultura intensiva, com fortes investimentos em mecanização e tecnologia, consistindo em produções especializadas com elevado incremento de capital.

Com relação aos dados de área colhida e dos valores obtidos com a produção da soja, é notório o destaque dos municípios de Ubiratã, Mamborê, Campo Mourão, Luiziana e Campina da Lagoa. Ubiratã (maior produtor regional) colheu em 2015 uma área de mais de 65 mil hectares com a soja e obteve 200 milhões de reais com a produção. Entretanto, para este município, quando observamos o Quadro 1 é possivel perceber que existe exagero nos dados do IBGE, pois a área colhida com a cultura da soja corresponde a área total do município. Os municípios de Mamborê e Campo Mourão figuram com aproximadamente $70 \%$ de suas terras ocupadas pela agricultura temporária da soja (cultivo de verão) e Luiziana e Campina da Lagoa com pouco menos de $50 \%$.

Mesmo que em uma significativa proporção dos municípios a area ocupada com a soja seja inferior a 60\%, pôde-se notar por meio da relação (Área colhida em hectares - Área total do município) que essa cultura tem grande impacto na produção desses municípios, resultando em altos percentuais da área municipal dedicada ao cultivo da soja. Exemplo dessa expressividade são os municípios de Juranda, Farol e Quarto Centenário que apresentam mais de $80 \%$ de seu territorio ocupado pela soja e Rancho Alegre d'Oeste com percentual acima de 70\% (Quadro 1).

Ademais, ao final do Quadro 1, estão representados os municípios que tiveram menor área colhida como: Barbosa Ferraz, Corumbataí do Sul, Iretama e Altamira do Paraná. Se obervar os mapas da Figura 2, nota-se que esses municípios situam-se na Subunidade 
Morfoescultural do Planalto do Alto/Médio Piquiri, com modelado do relevo mais acentuado, medianos índices de declividade e solos rasos, conformando condições mais propícias a outras culturas como as frutíferas e/ou pastagens.

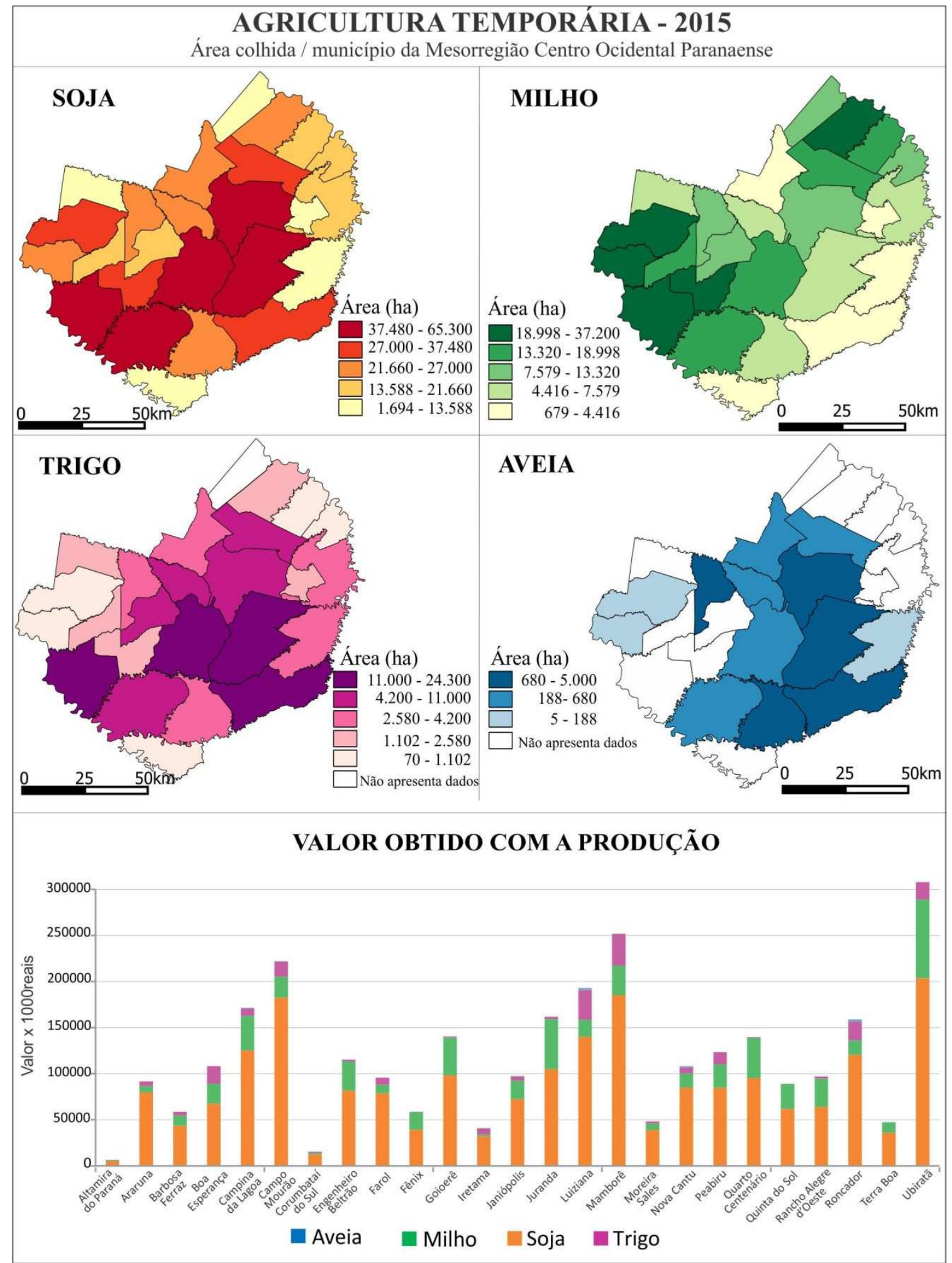

Figura 3: Agricultura Temporária - cultivos predominantes Fonte: Base Cartográfica - IBGE 2010; Dados - IBGE 2016 


\begin{tabular}{|c|c|c|c|c|}
\hline \multicolumn{5}{|c|}{ Cultura Temporária Predominante - Área Cultivada de Soja } \\
\hline Ranking dos Municípios & $\begin{array}{c}\text { Área Colhida } \\
\text { (ha) }\end{array}$ & $\begin{array}{c}\text { Área Colhida } \\
\left(\mathrm{Km}^{2}\right)\end{array}$ & $\begin{array}{c}\text { Área Total do } \\
\text { Município }\end{array}$ & $\begin{array}{c}\text { Percentual da área } \\
\text { municipal com Área } \\
\text { colhida de Soja }\end{array}$ \\
\hline 1ㅇ - Ubiratã & 65300 & 653 & 653 & 100,00 \\
\hline 2ㅇ - Juranda & 30950 & 309,5 & 350 & 88,43 \\
\hline 3ㅇ - Farol & 23800 & 238 & 289 & 82,35 \\
\hline 4으- Quarto Centenário & 25850 & 258,5 & 322 & 80,28 \\
\hline 5o - Rancho Alegre d'Oeste & 18950 & 189,5 & 241 & 78,63 \\
\hline 6o - Mamborê & 56200 & 562 & 788 & 71,32 \\
\hline 7ㅇ - Campo Mourão & 53500 & 535 & 758 & 70,58 \\
\hline 8o - Boa Esperança & 21300 & 213 & 307 & 69,38 \\
\hline 9o - Janiópolis & 21900 & 219 & 336 & 65,18 \\
\hline 10 - Quinta do Sol & 19790 & 197,9 & 326 & 60,71 \\
\hline 11ㅇ - Peabiru & 27688 & 276,88 & 469 & 59,04 \\
\hline 12으 - Fênix & 13685 & 136,85 & 234 & 58,48 \\
\hline 13ㅇ - Engenheiro Beltrão & 27000 & 270 & 467 & 57,82 \\
\hline 14ㅇ - Araruna & 27000 & 270 & 493 & 54,77 \\
\hline 15ㅇ- Goioerê & 29400 & 294 & 564 & 52,13 \\
\hline 16ㅇ-Roncador & 37000 & 370 & 742 & 49,87 \\
\hline 170 - Campina da Lagoa & 39400 & 394 & 797 & 49,44 \\
\hline 18ㅇ - Luiziana & 42700 & 427 & 908 & 47,03 \\
\hline 19o - Nova Cantu & 22600 & 226 & 555 & 40,72 \\
\hline 20 - Moreira Sales & 13200 & 132 & 354 & 37,29 \\
\hline 21ㅇ - Terra Boa & 11500 & 115 & 321 & 35,83 \\
\hline 22ㅇ - Barbosa Ferraz & 13850 & 138,5 & 539 & 25,70 \\
\hline 23ㅇ- Corumbataí do Sul & 3705 & 37,05 & 164 & 22,59 \\
\hline 240 - Iretama & 10500 & 105 & 570 & 18,42 \\
\hline 25ㅇ - Altamira do Paraná & 1694 & 16,94 & 387 & 4,38 \\
\hline
\end{tabular}

Quadro1: Status dos municípios produtores de Soja na Mesorregião Centro Ocidental Paranaense

Fonte: Dados da agricultura (PAM-IBGE, 2016); Dados da área municipal (IBGE-Cidades, 2016).

Ainda analisando a Figura 2, no mapa de ditribuição da cultura do milho observa-se que, os municípios da Mesorregião Centro Ocidental Paranaense com maior área colhida em hectares (2015), foram: Engenheiro Beltrão, Goioerê, Quarto Centenário, Juranda e Ubiratã. Ficando os demais como: Araruna, Corumbataí do Sul, Iretama, Roncador e Altamira do Paraná num nível intermediario. A cultura do milho é muito exigente em água, a ocorrência de déficit hídrico pode ocasionar danos em todas as fases fenológicas da planta, e consequentemente influenciar nos resultados da produção. Solos porosos e profundos como os Latossolos ajudam na drenagem e conservação da água disponibilizando para as culturas quando necessário. Contudo, esses critérios são para o milho de verão, já o milho safra de inverno fica mais sujeito aos eventuais percalços climáticos.

Com relação ao trigo (cultura de inverno), os municípios que tiveram maior área colhida foram: Ubiratã, Mamborê, Luiziana e Roncador. E menor área colhida: Goioerê, Quarto Centenário, Terra Boa, Quinta do Sol e Fênix. O trigo é uma cultura que pode ser 
considerada de "risco" em razão de diversos fatores, destre eles destacam-se as condições climáticas, o ataque de pragas e a ocorrência de doenças, o que demanda controle (assistência técnica constante) e como se trata de agricultura tecnificada depende do uso de equipamentos agrícolas para realização de tratos culturais.

Para o cultivo da aveia (cultura de inverno), nota-se que os municípios que tiveram mais área colhida foram os localizados de sudeste a sul da mesorregião, áreas caracterizadas por apresentarem menores temperaturas como: Janiópolis, Campo Mourão, Luiziana, Roncador e Nova Cantu. E com menos área colhida: Terra Boa, Engenheiro Beltrão, Quinta do Sol, Fênix, Barbosa Ferraz, Corumbataí do Sul e Moreira Sales. A inserção da aveia no sistema de produção justifica-se em decorrência das suas múltiplas formas de utilização, aveia preta como forrageira, corte, pastejo, feno ou silagem para os animais e como cultura de cobertura verde do solo. A aveia branca, ao contrário, é usada na alimentação humana, na forma de farinha, flocos, barras de cereal, biscoitos, pães e farelo. Este cultivo, assim como o trigo exige condições climáticas ideais, tratos culturais adequados, solos com boa fertilidade, assistência técnica, além de luminosidade, umidade relativa do ar e suprimento hídrico, adequados para obtenção de bons rendimentos.

Na Figura 4, está um resumo do percentual de área utilizado com cada tipo de cultivo, das culturas temporárias, descritas e relacionadas anteriormente, ficando nítida a predominância das culturas de verão, soja e milho, em prol das culturas de inverno, trigo e aveia.

Somado aos fatores de ordem natural, que propiciam a prática da agricultura temporária com os produtos de maior projeção regional, merece destaque a articulação territorial promovida pela Cooperativa Agropecuária Mourãoense (COAMO), considerada a maior cooperativa da America Latina, tem sua sede localizada em Campo Mourão, e entrepostos em quase todos os municípios da mesorregião a qual influencia diretamente o desenvolvimento agrícola regional. A cooperativa oferece as atividades de suporte e assistência técnica aos cooperados, recebimento de grãos, venda de insumos, o que facilita a comercialização da produção agrícola, especialmente dos pequenos produtores. Desta forma, a agricultura temporária, com a finalidade de exportação, atendendo as exigências do mercado internacional, tem se desenvolvido amplamente na região, constituindo um marcante e repetitivo uso da terra na paisagem. 




Figura 4: Correlações de área colhida entre os cultivos predominantes Fonte: Base Cartográfica - IBGE 2010; Dados - IBGE 2016

Entre as culturas temporárias destaca-se ainda, a Cana de açúcar, a Mandioca e o Feijão (Figura 5). Ainda que elas não sejam representativas para todos os municípios da mesorregião, se desenvolvem em pequena parcela desses, porém com alta produtividade e forte incremento na arrecadação de renda. A cana de açúcar, além de atender demanda da indústria alimentícia, está sendo amplamente utilizada no setor dos biocombustíveis.

Os municípios que mais colheram cana de açúcar (em hectares) foram: Engenheiro Beltrão, Terra Boa, Quinta do Sol, Fênix, Barbosa Ferraz, Moreira Sales e Goioerê. Para o município de Engenheiro Beltrão, que apresentou maior área colhida da cana, no ano de 2015, o valor total obtido com a produção foi de trinta e cinco milhões de reais, relativamente alto considerando o desenvolvimento econômico regional.

A cana de açúcar é basicamente uma cultura de climas tropicais, com rendimentos significativamente afetados pela temperatura, umidade relativa e radiação solar, motivo 
pelo qual são encontrados em maior proporção nos municípios do norte da mesorregião, onde predominam as áreas do arenito Caiuá. O desenvolvimento da cana de açúcar nesses municípios é regido por usinas sucroalcooleiras presentes na região, as quais arrendam as propriedades rurais locais e se ocupam das etapas de plantio, manejo e colheita.



Figura 5: Agricultura temporária com destaque em algumas localidades Fonte: Base Cartográfica - IBGE 2010; Dados - IBGE 2016

Em relação à cultura da mandioca, os municípios de maior produção são: Araruna, Terra Boa, Janiópolis e Moreira Sales. É considerada uma planta rústica que apresenta adaptação às diversas condições de clima e solo, além de ser resistente e tolerante a pragas e doenças, não necessita de tratos culturais intensivos, motivo pelo qual é cultivado em pequenas propriedades. O município de Araruna destaca-se com a presença de Indústrias Alimentícias (Farinheiras), as quais incentivam a produção e fornecem assessoramento técnico, além de 
garantir ao produtor o mercado certo para a comercialização e alto valor agregado ao seu produto.

Outra cultura temporária que merece destaque nas análises é o feijão. Os agricultores têm investido nesse produto, conquistando mais espaço de produção nos municípios de Mamborê e Roncador, seguidos de Iretama e Barbosa Ferraz. O feijão apresenta sistema radicular que se desenvolve melhor em solos de textura areno-argilosa, ricos em matéria orgânica e em elementos fertilizantes. Contudo, é considerada uma cultura de risco climático, restringindo a área de ocupação na mesorregião, porém, em razão dos valores obtidos com a produção, os agricultores acreditam que vale a pena os riscos.

O mapa apresentado na Figura 6 indica os cultivos temporários de consumo local ou regional, a área total colhida por município e a proporcionalidade dos produtos: abacaxi; alho; amendoim; arroz; batata doce; batata inglesa; centeio; fumo; melancia; melão; rami e; tomate. Os municípios de maior destaque são Campina da Lagoa, Nova Cantu e Roncador, os quais se situam em áreas de relevo mais dissecado, o que impede a mecanização agrícola e ao mesmo tempo, encontram ambiente físico natural mais propício ao desenvolvimento de algumas dessas espécies.

Com relação à diversidade dos produtos cultivados (Figura 6), observa-se que ela ainda é baixa: Araruna e Barbosa Ferraz figuram com a maior diversificação agrícola, apresentam sete tipos de produtos; Campina da Lagoa, Corumbataí do Sul, Peabiru e Roncador cultivam seis tipos; Campo Mourão, Engenheiro Beltrão, Farol, Iretama, Mamborê, Moreira Sales e Quinta do Sol produzem cinco tipos; Fênix, Goioerê, Luiziana e Nova Cantu apresentam quatro tipos; Boa Esperança, Juranda e Ubiratã três tipos; Altamira do Paraná, Janiópolis e Terra Boa apenas dois tipos; Quarto Centenário um tipo e; Rancho Alegre do Oeste não apresentou dados.

Cabe salientar que, a área total ocupada com esses cultivos é pequena em todos os municípios (Figura 6), demonstrando a insuficiência relacionada à produção de alimentos para o consumo regional e até mesmo articulada para a comercialização externa. Enquanto a região se dedica a produção de grãos em larga escala, a demanda por alimentos é suprida com a compra de produtos de outros centros fornecedores. Conforme analisado 
anteriormente, esta situação decorre do alto percentual da área agrícola total que é utilizado com culturas comerciais de soja, milho e trigo.

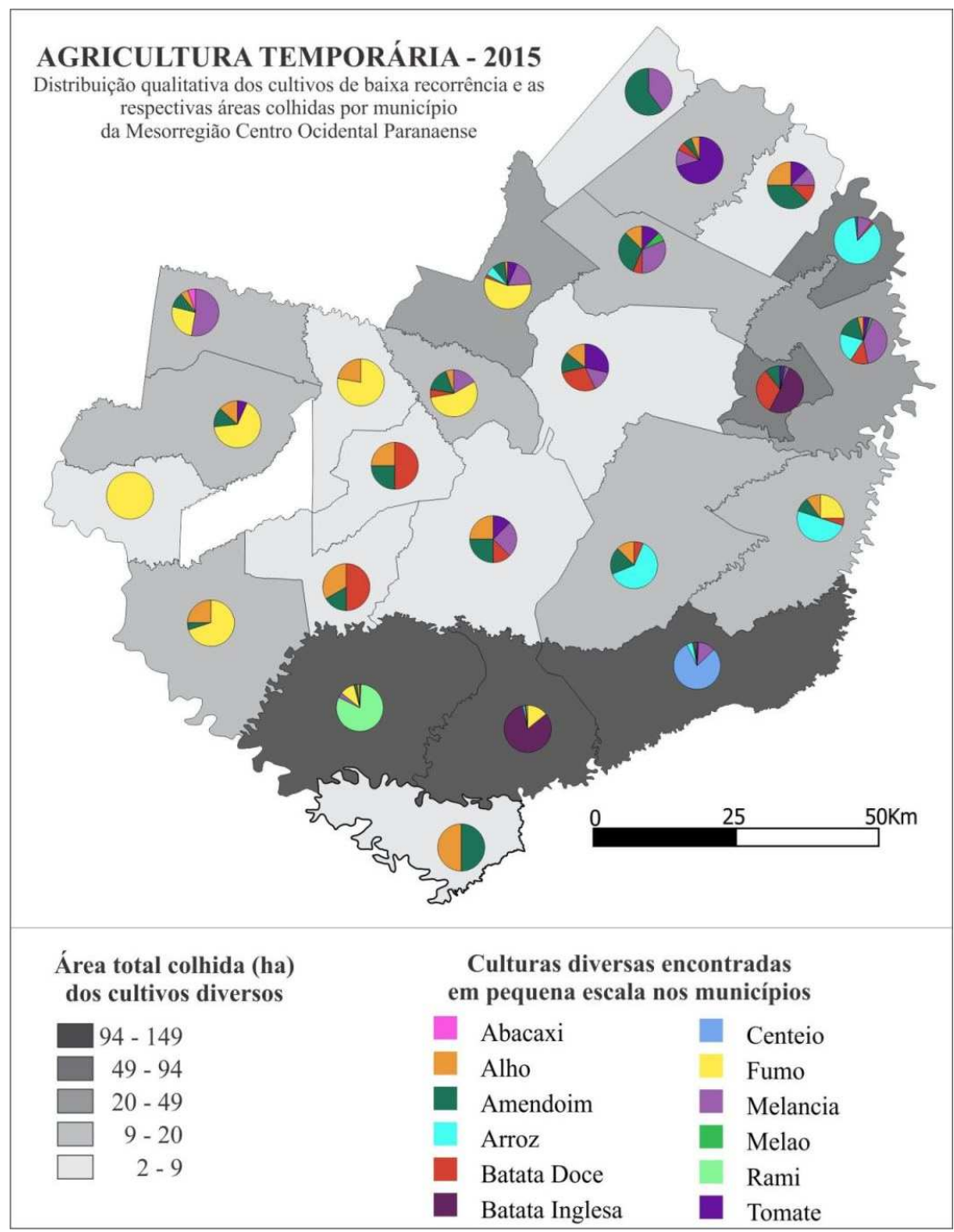

Figura 6: Agricultura temporária, produtos diversos Fonte: Base Cartográfica - IBGE 2010; Dados - IBGE 2016

Na Figura 7, apresenta-se um mapa da agricultura permanente, contendo as respectivas áreas colhidas e os valores obtidos com a produção nos municípios da mesorregião. Com relação aos tipos de cultivos da agricultura permanente, foram identificadas principalmente espécies frutíferas, as quais foram subdivididas em categorias de acordo com a proposta da Embrapa (Empresa Brasileira de Pesquisa Agropecuária) em Frutas de Clima Tropical, Frutas de Clima Temperado e Frutas Cítricas, para abranger os cultivos que não se enquadram em nenhuma dessas categorias adotou-se a categoria Culturas Diversas. 
Ao observar o conjunto de mapas, da Figura 7, evidencia-se que os cultivos permanentes são pouco difundidos, da mesma forma (dados também observados na Figura 8), demonstram que a diversificação agrícola é baixa na maioria dos municípios. Em termos gerais, os municípios do setor leste apresentam maior engajamento com a produção permanente, estes apresentam relevo mais dissecado e solos rasos e, por este motivo, parcelas significativas de seus territórios não são passíveis de mecanização agricola para a produção de grãos. Portanto, os produtores encontram no cultivo de frutíferas e outras culturas permanentes a alternativa para o desenvolvimento e diverificação no uso da terra do meio rural.

Além dos aspectos físicos da paisagem, outro fator que merece destaque na análise consiste na criação da COAPROCOR (Cooperativa Agroindustrial de Produtores de Corumbataí do Sul e Região) que atende pequenos produtores de frutíferas no município de Corumbataí do Sul e entorno, influíndo diretamente na re-organização socioespacial de suas paisagens rurais. A instituição foi criada inicialmente com o nome de Amocor (1992), depois transformada em Aprocor (1997, Associação de Produtores de Corumbataí do Sul - PR), e tinha o objetivo de fomentar a cafeicultura buscando agregar valor ao café produzido na região e melhorar as condições para inserção no mercado. Com as constantes perdas de safras do café, decorrentes dos azares climáticos (sucessivas geadas), a associação, que depois se transformou em cooperativa, optou por investir na diversificação da agricultura, especialmente na fruticultura (MASSOQUIM, 2010; COLAVITE, PASSOS, 2010; COLAVITE, 2013).

Dentre as frutas de clima tropical o produto de maior destaque é o Maracujá e, de acordo com Massoquim (2010, p.255), "foi da APROCOR o incentivo de formar uma cadeia de produção e de implantação do produto", os plantios tiveram início no ano de 2000 em Corumbataí do Sul e aos poucos foi se expandindo por vários municípios do entorno, tanto da Mesorregião Centro Ocidental Paranaense (vide figura 7), quanto das regiões vizinhas. $\mathrm{Na}$ atualidade, já como Cooperativa (COAPROCOR), existe todo um sistema de armazenamento e beneficiamento industrial deste e de outros produtos.

As frutíferas, apesar de serem de clima tropical, adaptam-se perfeitamente ao subtropical, caso da mesorregião que se situa em uma área de transição a $60 \mathrm{~km}$ ao Sul do Paralelo de Capricórnio (MASSOQUIM, 2010). Com relação às frutas, além do maracujá, merecem 
destaque os cultivos de banana e abacate, os quais estão presentes em quase todos os municípios da região, a goiaba, a manga e o mamão são cultivados em pequenas áreas em alguns municípios.

Para as frutas de clima temperado/subtropical a de maior destaque regional é a uva, presente na maioria dos municípios, embora seu cultivo ocorra em pequenos espaços, sua rentabilidade é alta se comparada aos demais produtos. Outros frutos como o pêssego, o caqui e o figo, são produzidos em pequenas áreas de municípios a leste da mesorregião.

Já com relação ao cultivo de frutas cítricas, o produto de maior destaque é a laranja, com presença significativa nos municípios da região. Essa cultura adapta-se praticamente a todos os tipos de solo, e necessita de pouca manutenção se comparada às demais. O município de Terra Boa é o que apresentou maior área de produção da laranja, tal fato deve-se a sua posição geográfica em relação ao noroeste do Paraná, região com tradição na produção desta fruta. Os cultivos de limão e tangerina são mais restritos e produzidos apenas em alguns municípios.

O último mapa da Figura 7 representa os cultivos permanentes diversos, dos quais destacamos o café e a erva mate por apresentarem maior expressividade no cenário regional. O cultivo de café está presente em 17 dos 25 municípios da Mesorregião Centro Ocidental Paranaense. A cafeicultura fez parte da história da região pesquisada, a qual foi colonizada com a intenção da inserção deste plantio, seguindo o processo já estabelecido no norte do estado do Paraná. O ciclo do café no Paraná, para Cancian (1981, p.13) constituiuse na "continuação da 'marcha para Oeste' dos paulistas, que sempre a procura de perspectiva de lucros adentraram o Paraná". Isso num momento em que as terras do estado de São Paulo já estavam escassas e supervalorizadas.

Entretanto a cultura não se desenvolveu em todos os municípios, especialmente em razão das condições climáticas, o limite latitudinal prioritário para sua implantação é o paralelo 24ำ Sul, porém extrapolou essa linha, ficando suceptível aos azares climáticos. O ciclo do café na mesorregião foi curto, poucos anos após seu início instalou-se o processo de modernização da agricultura e rapidamente o cultivo recém-implantado foi substituído pela agricultura temporária de grãos. Apesar de lucrativa, apenas alguns municípios se destacam nessa atividade, em primeiro lugar figura Corumbataí do Sul com a maior área de produção 
(no qual os cafezais são predominantes na paisagem rural), seguido por Araruna, Peabiru, Barbosa Ferraz e Terra Boa.



Figura 7: Agricultura Permanente

Fonte: Base Cartográfica - IBGE 2010; Dados - IBGE 2016 
A erva mate é outro produto que fez parte das primeiras culturas de exploração econômica no Estado do Paraná e de sua história. Uma planta nativa, explorada de forma extrativista no inicio do século $X X$, e que aos poucos tem retornado ao cenário agrícola, figurando na economia paranaense, com tendência de expansão decorrente dos altos preços de mercado.

O gráfico presente na figura 8 ilustra o ranqueamento dos municípios da mesorregião, considerando a área total de cada um empregada na agricultura permanente. Nele fica evidente o destaque do município de Corumbataí do Sul, o qual apresenta a menor área territorial da mesorregião $\left(164 \mathrm{Km}^{2}\right)$ porém, com a maior área de agricultura permanente, seguido por Barbosa Ferraz, Terra Boa, Araruna, Iretama e Roncador.

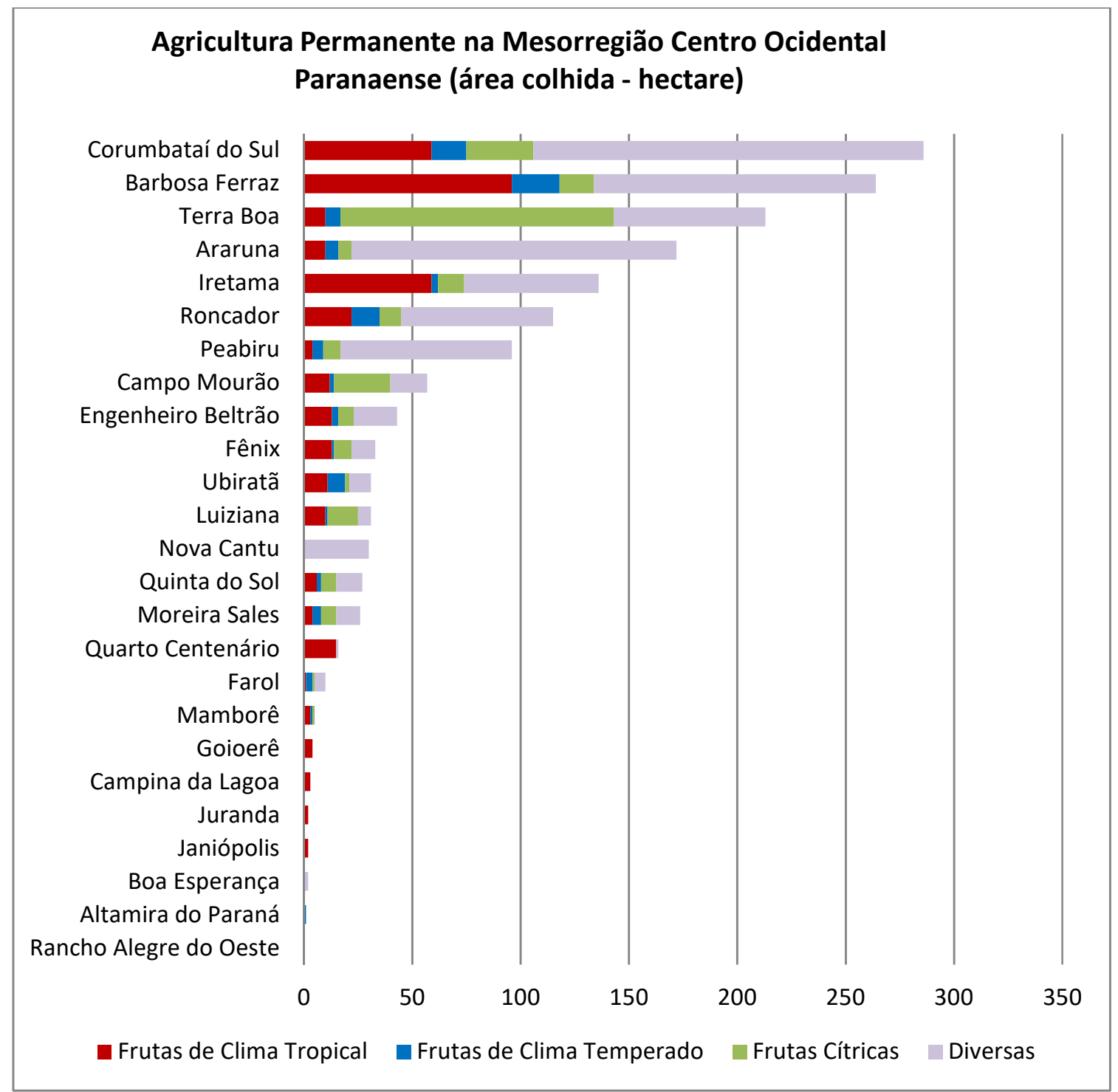

Figura 8: Relação da área colhida (hectare) por tipo de cultivo temporário, por município da Mesorregião Centro Ocidental Paranaense

Fonte: Base Cartográfica - IBGE 2010; Dados - IBGE 2016 


\section{Considerações finais}

As correlações entre agricultura e paisagem estão fortemente presentes nos municípios da Mesorregião Centro Ocidental Paranaense. Nestes, pode-se observar o alto índice de investimento de capital no campo e a adoção da agricultura mecanizada e de precisão, especialmente nos espaços onde a conformação do meio natural assim o propicia.

É fato comprovado, pelos dados apresentados neste artigo, que a agricultura voltada à exportação, neste caso salientamos a soja e o milho, são os cultivos de maior destaque e predominância no cenário regional. Ao observar a paisagem percebe-se que essas culturas estão presentes em quase todos os espaços onde é possível a mecanização.

O desenvolvimento regional e o dinamismo socioeconômico local dependem diretamente das atividades desenvolvidas no espaço rural, especialmente às oriundas do agronegócio, articuladas pelas grandes cooperativas agroindustriais. No caso da cana de açucar e da mandioca, as quais mesmo particularizadas em alguns munícipios, também têm as atividades geridas por grandes agroindustrias e impactam as cidades onde se inserem.

A produção olerícola de alimentos é insipiente e os municipios ficam à merce de mercados externos. Da mesma forma, a produção de cultivos permanentes é pouco difundida regionalmente, se restringindo a alguns municípios e em pequenas porções de terra. É necessário que a sociedade se organize e o poder público, local e estadual, criem condições para incentivar e apoiar as pequenas cooperativas já existentes e que novas sejam criadas com intuito de atender a parcela dos produtores rurais que não são contemplados pelas políticas do agronegócio.

Outra questão que não pôde deixar de ser contemplada na análise foi a necessidade de processar os produtos que na atualidade são vendidos in natura. O processo industrial agrega valor aos produtos, amplia a oferta de empregos, movimenta e dinamiza as cidades, além de gerar mais impostos se comparado ao setor primário. 


\section{Referências bibliográficas}

ANDRADE, Áurea Andrade Viana de. Poder, Estado e Capital nos processos Des-re-territorialização no campo, na microrregião geográfica de Campo Mourão. 2013. 310f. Tese (Doutorado em Geografia) - Universidade Estadual de Maringá. Maringá, 2013.

ANDRADE, José Antônio. As unidades de paisagens e os sistemas de produção agrícolas no município de Floraí$P R$. 116f. Tese (Programa de Pós Graduação em Geografia Mestrado) Departamento de Geografia do centro de Ciências Humanas, Letras e Artes da Universidade Estadual de Maringá. Maringá, 2005.

BERTRAND, Georges. Paisagem e Geografia Física Global: esboço metodológico. Caderno de Ciências da Terra, 1972,13,1-27.

CANCIAN, Nadir Aparecida. Cafeicultura Paranaense-1900/1970. Curitiba: GRAFIPAR, 1981.

COLAVITE, Ana Paula. As transformações históricas e a dinâmica atual da paisagem de Corumbataí do Sul Paraná. 224f. Tese (Doutorado em Geografia) - Universidade Estadual de Maringá, Maringá, 2013.

COLAVITE, Ana Paula; MASSOQUIM, Nair Glória. O relevo e a paisagem em Corumbataí do Sul, Paraná. In: Giovanni Seabra. (Org.). Educação Ambiental - O Capital Natural na Economia Global. 1ed.Ituiutaba/MG: Barlavento, 2016. p. 241-255.

COLAVITE, Ana Paula; PASSOS, Messias Modesto dos. Papel da APROCOR na inserção de Corumbataí do Sul na rede urbana de produção da fruticultura e olericultura. In: V EPCT, 2010, Campo Mourão - PR, Anais..., 2010.

EMBRAPA. Cultivos. Disponível em: https://www.embrapa.br/. Acesso: janeiro de 2018.

EMBRAPA. Sistema brasileiro de classificação de solos. 2.ed. Rio de Janeiro: EMBRAPA Solos, 2006.

FAJARDO, Sergio. Territorialidades Cooperativas no Rural Paranaense. Guarapuava: Editora UNICENTRO. 2008.

FERREIRA, D.A.O; HESPANHOL, R.A.M; SALAMONI, G. Agricultura, Desenvolvimento Regional e Transformações Socioespaciais. Revista da Associação Nacional de Pós graduação e Pesquisa em Geografia (Anpege), v.12, n.18, especial GT Anpege 2016, p.25-42.

GRAZIANO DA SILVA, José. O que é Questão Agrária. 1ạ ed. São Paulo: Brasiliense, 1980. (Coleção Primeiros Passos)

GREIDER, T.; GARKOVICH, L. Landscapes: The Social Construction of Nature and the Environment. Rural Sociology, v.59, n.1, 1994.

HESPANHOL, Antonio Nivaldo. A formação sócio-espacial da região de Campo Mourão e dos municípios de Ubiratã, Campina da Lagoa e Nova Cantu - PR. Boletim de Geografia, dez. 1993, 11(1), 67-88.

HESPANHOL, Antonio Nivaldo. Desafios da geração de renda em pequenas propriedades e a questão do desenvolvimento rural sustentável no Brasil. In: ALVES, A.; CARRIJO, B.; CANDIOTTO, L.. (Org.). Desenvolvimento territorial e agroecologia. 1ed.São Paulo: Expressão Popular, 2008, v. 1, p. 81-94.

IBGE. Produção Agrícola Municipal - 2015. Rio de Janeiro: IBGE, 2016.

JACINTO, Janério Manoel; MENDES, César Miranda; PEREHOUSKEl, Nestor Alexandre. O rural e o urbano: contribuições para a compreensão da relação do espaço rural e do espaço urbano. Percurso, Maringá, v. 4, n. 2, p. 173- 191, 2012.

LACERDA, G.N. Capitalismo e produção familiar na agricultura. Universidade de São Paulo, Faculdade de Economia e Administração, Dissertação de Mestrado, 1983.

MASSOQUIM, Nair Glória. Clima e Paisagem da Mesorregião Centro Ocidental Paranaense. 2010. 399f. Tese (Doutorado em Geografia Física) - Faculdade de Filosofia, Letras e Ciências Humanas, Universidade de São Paulo. São Paulo, 2010.

MAXIMIANO, Liz Abad. Considerações sobre o conceito de paisagem. Raega - O Espaço Geográfico em Análise, 2004, 8, 83-91.

MINEROPAR. Atlas Geomorfológico do Estado do Paraná. Curitiba, 2006. 
MORO, Dalton Aureo. A Modernização da Agricultura Paranaense. In: VILLALOBOS, Jorge Guerra (Org.). Geografia Social e Agricultura no Paraná. Maringá: Programa de Pós-graduação em Geografia - UEM, 2001.

NORDER, Luiz A.C. Mercantilização da agricultura e desenvolvimento territorial. In: SCHNEIDER, S. (Org.) $A$ Diversidade da Agricultura Familiar. Porto Alegre: Ed. UFRGS, 2006. p.57-81.

PASSOS, Messias Modesto dos. Amazônia: teledetecção e colonização. São Paulo: Fundação Editoda da UNESP, 1998.

QGIS Development Team, 2016. QGIS Geographic Information System, versão 2.16. Open Source Geospatial Foundation Project. Disponível em: https://qgis.org. Acesso: setembro de 2016.

RAFFESTIN, Claude. A Produção das Estruturas Territoriais e sua Representação. In: SAQUET, Marcos Aurelio; SPOSITO, Eliseu Savério (Orgs.). Territórios e territorialidades: teorias, processos e conflitos. São Paulo: Expressão Popular, 2009. p.17-36.

SAUER, Carl O. A Morfologia da Paisagem. In: CORRÊA, Roberto Lobato; ROSENDAHL, Zeny (Org.). Paisagem, Tempo e Cultura. 2ed. Rio de Janeiro: EdUerj, 2004.

SAYER, Jeffrey et al. Ten principles for a landscape approach to reconciling agriculture, conservation, and other competing land uses. PNAS, 21, 2013, p.110-131.

SILVA, Rafael Pereira da; MARTINS, Angélica Verônica de Oliveira; ARAÚJO, Paulo César de. A utilização do geoprocessamento e da cartografia nos estudos agropecuários: um estudo de caso para a Região Metropolitana de Natal. Revista Sociedade e Território, Natal, v. 26, no 2, p. 92 - 108, jul./dez. 2014.

SOTCHAVA, V.B. O estudo de Geossistemas. Métodos em Questão. Instituto de Geografia, USP. n.16, São Paulo, 1977.

TRICART, J. Ecodinâmica. Rio de Janeiro: IBGE, Diretoria Técnica, SUPREN, 1977.

TSCHARNTKE, Teja; KLEIN, Alexandra M.; KRUES, Andreas; STEFFAN-DEWENTER, Ingolf; THIES, Carsten. Landscape perspectives on agricultural intensification and biodiversity - ecosystem service management. Ecology Letters, 8, p. 857-874, 2005.

YOKOO, Edson Noriyuki. Dinâmica das frentes de ocupação territorial na Mesorregião Centro-Ocidental Paranaense. 2013. 218f. Tese (Doutorado em Geografia) - Universidade Estadual de Maringá. Maringá, 2013. 